\title{
Complex Regulation of Spiral Ganglion Neuron Firing Patterns by Neurotrophin-3
}

\author{
Zhiping Zhou, Qing Liu, and Robin L. Davis \\ Department of Cell Biology and Neuroscience, Rutgers University, Piscataway, New Jersey 08854
}

\begin{abstract}
Auditory information is conveyed into the CNS via the spiral ganglion neurons, cells that possess distinctive electrophysiological properties that vary according to their cochlear innervation. Neurons from the base of the cochlea fire action potentials with shorter latencies and durations with more rapid accommodation than apical neurons (Adamson et al., 2002b). Interestingly, these features are altered by exposure to brain-derived neurotrophic factor and neurotrophin-3 (NT-3), suggesting that the electrophysiological diversity is not preprogrammed into the neurons but instead results from extrinsic regulation. In support of this, gradients of neurotrophins exist in the cochlea that could account for the apex-base differences in firing. To understand the determinants of spiral ganglion function, we characterized the NT-3 concentration dependence and mode of action on spiral ganglion neurons. Whole-cell current-clamp recordings were made from mouse basal spiral ganglion neurons (postnatal day 5) exposed to different concentrations of NT-3 for $3 \mathrm{~d}$ in vitro. Measurements of accommodation, latency, onset time course, and action potential latency revealed a nonmonotonic dependence on NT-3 concentration, with a peak effect occurring at $10 \mathrm{ng} / \mathrm{ml}$. Addition of NT-3 at different time points showed that neurotrophin exposure altered the firing features of existing neurons rather than supporting differential survival. These experiments establish that the electrophysiological phenotype of spiral ganglion neurons depends critically on the precise concentration of NT-3 and that the functional organization of this component of the peripheral auditory system results from a complex interplay between multiple kinds of neurotrophins and their cognate receptors.
\end{abstract}

Key words: NT-3; trkB; spiral ganglion; neurotrophin; hearing; cochlea

\section{Introduction}

Sound perception begins in the cochlea where ionic currents generated in the mechanoreceptive cells are conveyed via neurotransmitter receptors to the first neuronal element: the spiral ganglion neurons. The regimented structure of this sensory end organ, the organ of Corti, makes it a compelling model to study both development and sensory processing (Rubel and Fritzsch, 2002). The precise frequency resolution of the cochlea is conferred by myriad mechanical and electrical specializations in the organ of Corti that are systematically graded from the highfrequency, basal region to the low-frequency, apical region (Miller et al., 1997; Raphael and Altschuler, 2003).

Not unexpectedly, apex-base gradations also are found in the spiral ganglion neurons that convey their synaptic input to the brain. Morphological analysis has shown that neurons in the basal region have larger cell soma than those in the apical region (Liberman and Oliver, 1984; Felix et al., 1990; Nadol et al., 1990), presumably to conduct neural impulses at different rates. Elec-

Received May 1, 2005; revised June 12, 2005; accepted July 7, 2005.

This work was supported by National Institutes of Health Grant R01 DC01856. We thank Dr. Mark R. Plummer for his critical reading of this manuscript and Hui Zhong Xue for her expert tissue culture and immunocytochemical contributions.

Correspondence should be addressed to Dr. Robin L. Davis, Department of Cell Biology and Neuroscience, Rutgers University, 604 Allison Road, Nelson Laboratories, Piscataway, NJ 08854. E-mail: rldavis@rci.rutgers.edu.

Z. Zhou's present address: Department of Neuroscience and Cell Biology, University of Medicine and Dentistry of New Jersey, Robert Wood Johnson Medical School, Piscataway, NJ 08854.

D0I:10.1523/JNEUROSCI.1735-05.2005

Copyright $\odot 2005$ Society for Neuroscience $\quad$ 0270-6474/05/257558-09\$15.00/0 trophysiological studies from our laboratory have demonstrated that basal neurons also have rapid onset kinetics, short latencies, and fast accommodation, whereas apical neurons display slower onset kinetics, prolonged latencies, and heterogeneous characteristics that includes slow accommodation (Adamson et al., 2002b). We also showed these electrophysiological phenotypes were regulated by neurotrophins. Chronic exposure to brainderived neurotrophic factor (BDNF) caused neurons to fire with faster accommodation and kinetics, whereas neurotrophin-3 (NT-3) had the opposite effect (Adamson et al., 2002a). These data suggest that the firing patterns may result from differing levels of neurotrophins and/or tyrosine kinase (trk) receptors (Davis, 2003), a hypothesis supported by the presence of both trkB and trkC high-affinity trk receptors in the spiral ganglion (Ylikoski et al., 1993; Mou et al., 1997; Cochran et al., 1999; Gestwa et al., 1999) and graded NT-3, BDNF, and trkB levels in the adult cochlea and spiral ganglion neurons, respectively (Fritzsch et al., 1997; Schimmang et al., 2003).

The influence of two neurotrophins with opposing gradients and opposite actions on spiral ganglion neurons, coupled with the fact that NT-3 could have multifaceted effects because of its ability to bind to multiple receptor types, indicates that regulation of firing patterns could be quite complex. In the present study, we begin to unravel this complexity by examining the concentration-dependent effects of NT-3 on basal spiral ganglion neurons. By limiting our analysis to a restricted region of the cochlea, we dissected out an intricate relationship between spe- 
cific electrophysiological parameters and NT-3 concentration. We found that low concentrations of NT-3 produced the expected slowing of neuronal firing but that these effects were reversed at concentrations $>10 \mathrm{mg} / \mathrm{ml}$. This nonmonotonic relationship may result from activation of trkB and/or the p75 neurotrophin receptor ( $\mathrm{p} 75 \mathrm{NTR}$ ) at high NT-3 concentrations (Segal, 2003), thus modulating the endogenous membrane properties of the previously fast basal neurons. These findings have important implications for how a highly ordered sensory ganglion is organized and have implications for the molecular mechanisms involved in NT-3 modulation of these primary sensory neurons in the fully developed ear.

\section{Materials and Methods}

Tissue culture. Experiments were performed on CBA/CaJ mouse spiral ganglion neurons. Neonatal animals [postnatal day 5 (P5)] were decapitated, and both inner ears were removed from the base of the cranium. The spiral ganglion was isolated and divided into thirds; base sections were plated as explants in culture dishes coated with poly-L-lysine. For a single plating, one to four littermates were used to obtain a set of two to eight $35 \mathrm{~mm}$ culture dishes. In a limited set of experiments, the entire spiral ganglion was isolated and placed into tissue culture. In all cultures, cells were maintained in the following growth medium: DMEM, supplemented with $10 \%$ fetal bovine serum, $4 \mathrm{~mm}$ L-glutamine, and $0.1 \%$ penicillin-streptomycin. Neurons were maintained in culture at $37^{\circ} \mathrm{C}$ in a humidified incubator with $5 \% \mathrm{CO}_{2}$. NT-3 was purchased from PeproTech (Rocky Hill, NJ), dissolved in sterile deionized water at the concentration of $10 \mathrm{mg} / \mathrm{ml}$, and stored at $-20^{\circ} \mathrm{C}$ in aliquots of $10 \mu$ l. Just before use, the stock solution was diluted to different concentrations with sterile deionized water: $1,1.4,2,2.8$, and $4 \mathrm{mg} / \mathrm{ml}$ were used for the $5,7,10,14$, and $20 \mathrm{ng} / \mathrm{ml}$ groups, respectively. Because the culture dishes contained 2 $\mathrm{ml}$ of medium, $10 \mu \mathrm{l}$ of each of the dilutions was added to obtain the final concentration for each group.

Electrophysiology. The whole-cell configuration of the patch-clamp technique was used to obtain current-clamp recordings from spiral ganglion neurons in vitro. Pipettes were pulled on a two-stage vertical puller (PP-83; Narishige, Tokyo, Japan); the shafts were coated with Sylgard184 (Dow Corning, Corning, NY) to reduce transmural capacitance. Just before use, electrode tips were fire-polished (Narishige MF-83 microforge); electrode resistances typically ranged from 4 to $6 \mathrm{M} \Omega$ in standard pipette and bathing solutions. Pipette offset current was zeroed immediately before contacting the cell membrane. Pipette capacitance was compensated after the seal was formed with the low-pass filter set to $5 \mathrm{kHz}$. Current-clamp measurements were made with the $I_{\text {fast }}$ circuitry of the Axopatch 200A amplifier (Molecular Devices, Union City, CA). Neurons were held at $-80 \mathrm{mV}$ by injecting a sustained hyperpolarizing current $(-50$ to $-130 \mathrm{pA})$. Current pulses of $240 \mathrm{~ms}$ duration were injected at the interval of $5 \mathrm{~s}$ to test the electrical properties of the neurons. Care was taken to ensure that the voltage drop across pipette resistance was negligible. A standard set of solutions was used to approximate physiological conditions. The basic internal solution was as follows (in $\mathrm{mm}$ ): $112 \mathrm{KCl}$, $2 \mathrm{MgCl}_{2}, 0.1 \mathrm{CaCl}_{2}, 11$ EGTA, and 10 HEPES, pH adjusted to 7.35 by $\mathrm{KOH}$. In a limited set of experiments, $0.05 \%$ Lucifer yellow (L0144; Sigma, St. Louis, MO) or 1 8-hydroxypyrene-1, 3, 6-trisulfonic acid (pyranine; H1529; Sigma) was added to the intracellular solution to label the cell from which the recording was made. The bath solution contained the following (in mM): $137 \mathrm{NaCl}, 5 \mathrm{KCl}, 1.7 \mathrm{CaCl}_{2}, 1 \mathrm{MgCl}_{2}, 17$ glucose, 50 sucrose, and 10 HEPES, $\mathrm{pH}$ adjusted to 7.45 by $\mathrm{NaOH}$.

Recordings were made at room temperature $\left(\mathrm{RT} ; 19-22^{\circ} \mathrm{C}\right)$. Most recordings were made within $90 \mathrm{~min}$ of replacement of culture medium with bath solution immediately after taking the culture out of the incubator. Signals were digitized with an Indec IDA 15125 interface (Indec Systems, Sunnyvale, CA) in an IBM (White Plains, NY)-compatible personal computer; the programs for data acquisition and analysis were written in Borland $\mathrm{C}^{++}$and Microsoft Visual Basic (generously contributed by Dr. Mark R. Plummer, Rutgers University). The voltage signal was low-pass filtered at $2 \mathrm{kHz}$ and digitized at $10 \mathrm{kHz}$. Current-clamp recordings were considered acceptable when they met the following cri- teria: stable membrane potentials, low noise levels, discernible membrane time constant during the onset of step current injection, and overshooting action potentials (magnitudes of at least $80 \mathrm{mV}$ ). If any of these parameters changed during an experiment, indicating compromised cell health or metabolic failure, the remaining data were not analyzed.

Immunocytochemistry. Neuron-specific markers were used to analyze neuronal survival in cultures prepared similarly to those evaluated electrophysiologically. Tissues was fixed with methanol at $-20^{\circ} \mathrm{C}$ for $6 \mathrm{~min}$ and subsequently washed three times with $\mathrm{PBS}, \mathrm{pH} 7.35$, to remove residual methanol. Nonspecific antibody binding was blocked with 5\% normal goat serum (NGS; S-1000; Sigma), incubated either for 12-16 h at $4^{\circ} \mathrm{C}$ or for $1 \mathrm{~h}$ at RT $\left(19-22^{\circ} \mathrm{C}\right)$. The population of type II spiral ganglion neurons in our cultures was assessed with anti-peripherin antibody (AB1530; Chemicon, Temecula, CA) diluted at 1:4000 and incubated for $6-8 \mathrm{~h}$ at $4^{\circ} \mathrm{C}$. After the primary antibody was removed by washing (three times with PBS for $5 \mathrm{~min}$ ), the anti-peripherin antibody was labeled with tetramethylrhodamine isothiocyanate-conjugated antirabbit secondary antibody (1:100; $1 \mathrm{~h}$ at RT; T 6778; Sigma). With this procedure, we determined that the percentage of peripherin-positive neurons remained lower than $10 \%$ in all conditions. To label the entire population of spiral ganglion neurons, the above procedure was repeated with neuronal class III anti- $\beta$-tubulin antibody (TuJ1; $1: 350$ dilution; $1 \mathrm{~h}$ at RT; Covance, Princeton, NJ), which was labeled with FITC-conjugated anti-mouse secondary antibody (1:100; $1 \mathrm{~h}$ at RT; F 4018; Sigma). All antibody solutions were prepared in PBS with $2.5 \%$ NGS.

Experimental protocol and statistical analysis. To evaluate timedependent effects of added NT-3, dishes of basal spiral ganglion neurons obtained from an individual plating were separated into two to four groups (supplemental Fig. 1, available at www.jneurosci.org as supplemental material), with each group containing one or two dishes. In the first two groups, basal spiral ganglion neurons were maintained in vitro for $3 \mathrm{~d}$ before patch-clamp recordings were made. One of these groups was supplemented with $5 \mathrm{ng} / \mathrm{ml} \mathrm{NT-3}$ immediately after isolation (5 $\mathrm{ng} / \mathrm{ml} 0 \mathrm{~d}$ ); the other was unsupplemented (control). The second two groups were maintained in vitro for $3 \mathrm{~d}$ before NT-3 $(5 \mathrm{ng} / \mathrm{ml} 3 \mathrm{~d})$ or 10 $\mu l$ of deionized water (vehicle) was added to the media; patch-clamp recordings were made at $6 \mathrm{~d}$ in vitro (div). Whenever possible, the two culture dishes from a single animal were placed into matched test/control groups (i.e., $5 \mathrm{ng} / \mathrm{ml} 0 \mathrm{~d}$ vs control or $5 \mathrm{ng} / \mathrm{ml} 3 \mathrm{~d}$ vs vehicle groups). Left and right sides were randomly placed. The electrophysiological and neuronal survival assessments were obtained from a total of 16 and 4 platings, respectively. For the dose-response relationship, additional concentrations of NT-3 $(7,10,14$, and $20 \mathrm{ng} / \mathrm{ml})$ were examined. Media was supplemented at 3 div; patch-clamp recordings were made at 6 div. For each concentration, recordings were made from cells obtained from three to six separate platings (four to nine total dishes per concentration). In most sessions, one to three successful recordings were obtained from each culture dish; neuronal properties within an experimental group were similar across platings and dishes from the same plating. Effects of NT-3 on electrophysiological parameters and neuronal survival were evaluated for statistical significance using Student's two-tailed $t$ test.

\section{Results}

Previous studies had demonstrated that neurotrophins applied at $5 \mathrm{ng} / \mathrm{ml}$ for 6-7 div are capable of altering the electrophysiological phenotype of postnatal spiral ganglion neurons in vitro (Adamson et al., 2002a). To understand better the physiological relevance and mechanism of action, the present study was designed to evaluate concentration- and time-dependent effects of NT-3 on spiral ganglion neurons in vitro. Toward this end, recordings were made from a total of 147 neurons subjected to eight different conditions. Neurons in the $5 \mathrm{ng} / \mathrm{ml} 0$ d condition $(n=18$ recordings) were supplemented with $5 \mathrm{ng} / \mathrm{ml} \mathrm{NT}-3$ at the time of tissue dissociation ( $0 \mathrm{div}$ ) and maintained in culture for $3 \mathrm{~d}$, after which electrophysiological recordings were made. This group was compared statistically with the control group $(n=18)$ that was not supplemented with NT-3, yet was maintained in culture for the 
same amount of time ( $3 \mathrm{div})$. The third experimental group (5 $\mathrm{ng} / \mathrm{ml} 3 \mathrm{~d}$ ) was designed to test whether the timing of NT-3 application could have an impact on the electrophysiological results. Neurons were isolated in the same manner as the previous groups, but the media was not supplemented with NT-3 until after a delay of 3 div. The neurons in this experimental group ( $n=23)$ were also exposed to NT-3 for $3 \mathrm{~d}$; therefore, subsequent patch-clamp recordings were performed at 6 div. The control for this group received only the vehicle $\left(10 \mu \mathrm{l}\right.$ of deionized $\mathrm{H}_{2} \mathrm{O} ; n=$ 30 ) at 3 div; recordings were also made at 6 div. The remaining experimental conditions were designed to test the concentration dependence of the effect. The media was supplemented with NT-3 at 3 div with $7,10,14$, or $20 \mathrm{ng} / \mathrm{ml}(n=9,14,11,24$, respectively). To be consistent with the vehicle and $5 \mathrm{ng} / \mathrm{ml} 3 \mathrm{~d}$ conditions, the recordings were made at 6 div so that the cultures were exposed to NT-3 for $3 \mathrm{~d}$.

The first step in the study was to determine whether exposure to NT-3 for $3 \mathrm{~d}$ instead of $6 \mathrm{~d}$ would still have an effect on the electrophysiological properties of basal spiral ganglion neurons. We initially chose to evaluate the level of accommodation in these experiments because this electrophysiological parameter is a robust measure of NT-3 action. Despite the fact that neurons were exposed to $5 \mathrm{ng} / \mathrm{ml} \mathrm{NT}-3$ for half the time of that reported previously (Adamson et al., 2002a), a clear difference in accommodation was found (Fig. 1 $a$, insets). Example voltage traces from a control basal neuron show the expected rapid accommodation in response to prolonged (240 ms) step depolarizations (Fig. 1a, left inset traces). In this case, the maximum number of action potentials (APmax) fired by the neuron was two, regardless of the level of depolarization achieved in response to the constant-current injections. This particular example showed the greatest APmax in the data set; all other control neurons fired only a single action potential in response to similar levels of current injection (Fig. $1 a$, gray bars). In contrast, many of the neurons treated with $5 \mathrm{ng} / \mathrm{ml}$ NT-3 for $3 \mathrm{~d}$ showed slow accommodation (Fig. 1a, black bars, right inset traces), similar to that observed in previous studies.

We next examined whether NT-3 must be present at the time of neuronal isolation to alter accommodation. In this experimental protocol, vehicle or NT-3 was applied for $3 \mathrm{~d}$ but not until the cells had been maintained for 3 div; therefore, the recordings were made at 6 div. Again, vehicle-treated neurons showed the rapid accommodation typical of postnatal spiral ganglion neurons isolated from basal cochlea. The example in Figure $1 b$ (left inset traces) shows a neuron that fired only a single action potential in response to a prolonged depolarization. This was representative of the APmax values of the full population of neurons that were evaluated in the vehicle condition (Fig. 1b, gray bars). Cells exposed to NT-3 after 3 div showed the same slow accommodation as those in which NT-3 was applied at the time of plating, indicating that the delay had no effect on the ability of the neurotrophin to alter spiral ganglion neuron firing patterns. The example recording shown in Figure $1 b$ (right inset traces) is representative of the many neurons that showed slow accommodation when exposed to NT-3 after a 3 d delay (Fig. 1b, black bars).

Although the effects of $5 \mathrm{ng} / \mathrm{ml} \mathrm{NT}-3$ had a profound effect on accommodation, we designed our next experiments to determine whether higher concentrations of NT-3 had an impact on the numbers of neurons that accommodated and on their firing patterns. We found that increasing NT-3 concentration applied at 3 div did not produce a simple saturating relationship; instead, the numbers of neurons that showed slow accommodation peaked at $10 \mathrm{ng} / \mathrm{ml}$ and then declined at higher concentrations of NT-3. The frequency histogram shown in Figure $2 a$ compares the effect
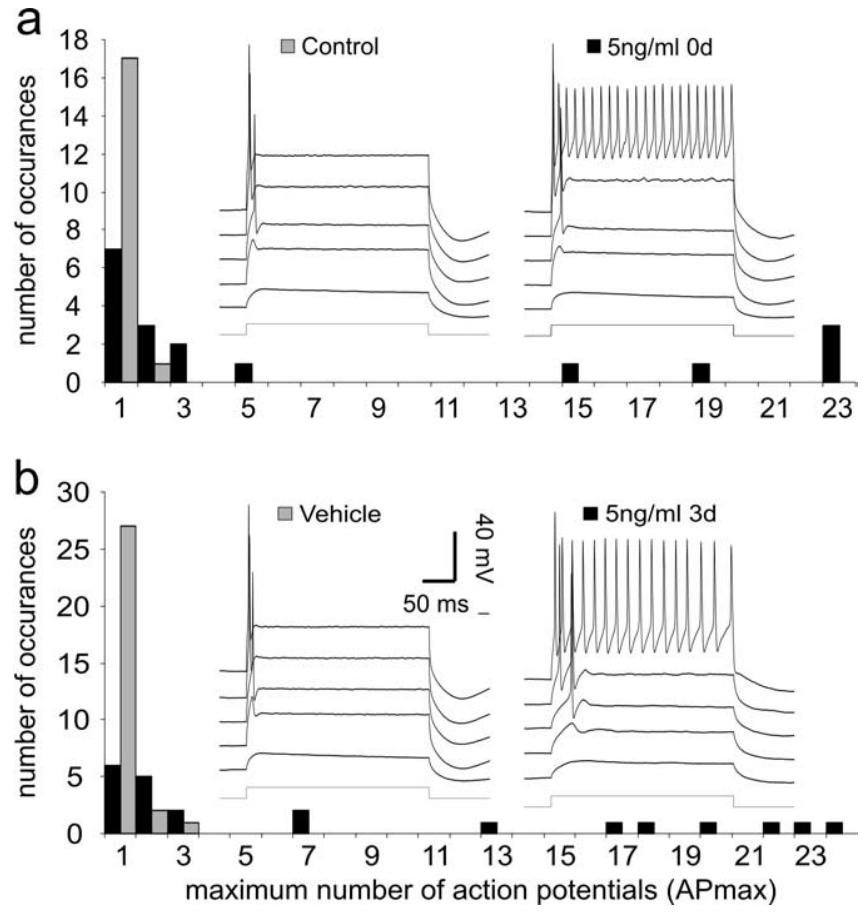

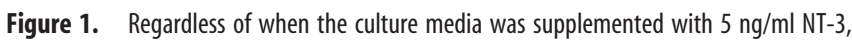
neurons showed a greater tendency to accommodate slowly in response to $240 \mathrm{~ms}$ step depolarizations when compared with their vehicle and control counterparts. $\boldsymbol{a}$, Frequency histogram of the maximum number of action potentials that fired in response to $240 \mathrm{~ms}$ step depolarizations obtained from the population of neurons recorded at 3 div, which were either untreated (gray bars) or exposed to $5 \mathrm{ng} / \mathrm{ml}$ NT-3 immediately after tissue isolation (black bars). Inset, The left set of voltage traces is from a neuron in the control group without NT-3 supplementation in culture for 3 div. The right set of voltage traces is from a neuron exposed to NT-3 immediately after tissue isolation ( 0 div); recordings were made at 3 div. $\boldsymbol{b}$, Frequency histogram of the maximum number of action potentials that fire in response to $240 \mathrm{~ms}$ step depolarizations obtained from the population of neurons recorded at 6 div, which received vehicle (gray bars) or $5 \mathrm{ng} / \mathrm{ml}$ NT-3 (black bars) at 3 div. Inset, The left set of voltage traces is from a neuron exposed to vehicle ( $10 \mu$ l of sterile distilled $\mathrm{H}_{2} \mathrm{O}$ ) at 3 div; recordings were made at 6 div. The right set of voltage traces is from a neuron exposed to $5 \mathrm{ng} / \mathrm{ml} \mathrm{NT}-3$ at 3 div; recordings were made at 6 div. In each inset, the voltage traces represent (from the bottom to top): command current, response to depolarization to $-70 \mathrm{mV}$, subthreshold response, threshold response, response to depolarization to $-40 \mathrm{mV}$; the top traces were responses to depolarization to $-35 \mathrm{mV}$. (In the left traces in each panel, this was measured at the plateau voltage. In the right voltage traces in each panel, this was determined by extrapolation.)

of 10 and $20 \mathrm{ng} / \mathrm{ml} \mathrm{NT-3}$ to vehicle recordings shown previously in Figure $1 b$. Of the 14 neurons exposed to $10 \mathrm{ng} / \mathrm{ml} \mathrm{NT-3}$, all displayed slow accommodation (APmax, 14-28) (Fig. 2a, dark gray bars). Increasing the concentration of NT-3 to $20 \mathrm{ng} / \mathrm{ml}$ actually decreased its efficacy: only 4 of 24 neurons fired more than five action potentials throughout the same duration depolarizing current injection (APmax, 1-21) (Fig. 2a, black bars).

These data were further quantified by averaging APmax for NT-3 concentrations ranging from 5 to $20 \mathrm{ng} / \mathrm{ml}$. As shown in Figure $2 b, 10 \mathrm{ng} / \mathrm{ml}$ had the largest effect $(21.9 \pm 1.0$ action potentials) with reduced efficacy at both lower and higher concentrations $(7.1 \pm 2.1,7.9 \pm 1.8,13.9 \pm 3.8,9.5 \pm 3.0,4.9 \pm 1.2$ action potentials for $5 \mathrm{ng} / \mathrm{ml} 0 \mathrm{~d}, 5 \mathrm{ng} / \mathrm{ml} 3 \mathrm{~d}, 7,14$, and $20 \mathrm{ng} / \mathrm{ml}$ respectively; $p<0.01$ for all comparisons). Importantly, we found that there were no differences between recordings made from neurons in control $(1.1 \pm 0.06)$ and vehicle $(1.1 \pm 0.08)$ cultures. Nor was there a difference in the APmax magnitude for recordings made from neurons exposed to $5 \mathrm{ng} / \mathrm{ml} \mathrm{NT}-3$ for the initial 0-3 div or for later exposures of 3-6 div. These compari- 


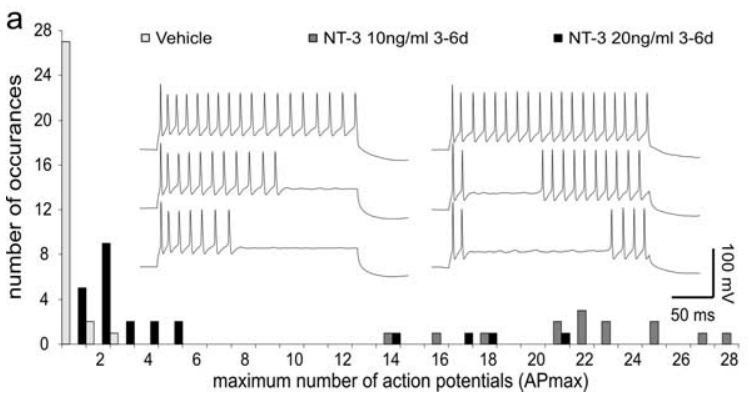
b

Figure 2. Neurons had the greatest tendency to accommodate slowly when exposed to an intermediate concentration of NT-3. $\boldsymbol{a}$, Frequency histogram of the maximum number of action potentials fired in response to a $240 \mathrm{~ms}$ step depolarization. Recordings were made from neurons at 6 div; vehicle (light gray bars), $10 \mathrm{ng} / \mathrm{ml} \mathrm{NT}-3$ (dark gray bars), and $20 \mathrm{ng} / \mathrm{ml} \mathrm{NT-3} \mathrm{(black} \mathrm{bars)} \mathrm{were}$ added to the culture media at 3 div. Inset, The left series of three traces recorded from a single neuron shows increasing numbers of action potentials fired in response to small incremental depolarizing current injections ( $240 \mathrm{~ms}$ duration). Note that the cell fires with relatively constant interspike intervals starting from the onset of the step depolarization; the APmax for this neuron was 23 . The right series of three traces from a single neuron shows a different firing progression with small depolarizing increments. A prominent delay is observed between the first two action potentials and the subsequent action potentials. The APmax for this cell was 22 . Both recordings were made at 6 div from neurons exposed to $10 \mathrm{ng} / \mathrm{ml}$ of NT-3 at 3 div. $\boldsymbol{b}$, Accommodation was quantified by averaging the APmax fired to a 240 ms duration step depolarization for recordings made from each experimental condition. The number of neurons included in each category for this and subsequent figures is as follows: control $(n=18)$, NT-3 at $5 \mathrm{ng} / \mathrm{ml} 0-3$ $\mathrm{d}(n=18)$, vehicle $(n=30), \mathrm{NT}-3$ at $5 \mathrm{ng} / \mathrm{ml} 3-6 \mathrm{~d}(n=23), \mathrm{NT}-3$ at $7 \mathrm{ng} / \mathrm{ml} 3-6 \mathrm{~d}(n=9), \mathrm{NT}-3$ at $10 \mathrm{ng} / \mathrm{ml} 3-6 \mathrm{~d}(n=14)$, NT-3 at $14 \mathrm{ng} / \mathrm{ml} 3-6 \mathrm{~d}(n=11)$, and NT- 3 at $20 \mathrm{ng} / \mathrm{ml} 3-6 \mathrm{~d}(n=24)$. Recordings made at 3 div were taken from untreated neurons (control) or neurons exposed to $5 \mathrm{ng} / \mathrm{ml} \mathrm{NT}-3$ immediately after isolation $(5 \mathrm{ng} / \mathrm{ml} 0 \mathrm{~d})$. Recordings were also made at 6 div from neurons exposed to vehicle, 5 ( $5 \mathrm{ng} / \mathrm{ml} 3 \mathrm{~d}), 7,10,14$, or $20 \mathrm{ng} / \mathrm{ml} \mathrm{NT}-3$, which was applied at 3 div. Bars represent the mean; error bars represent the SEM. Lines above the graph extending between error bars denote a significant difference between the two conditions using Student's two-tailed $t$ test. In this and subsequent figures, black lines represent a difference at the $p<$ 0.01 level, whereas gray lines represent a difference at the $p<0.05$ level. The $5 \mathrm{ng} / \mathrm{ml} 0 \mathrm{~d}$ condition is compared with the control; all other experimental conditions were compared with the vehicle.

sons indicate that NT-3 is equally efficacious regardless of whether it is applied at the time of plating or after 3 div.

Two alterations in the characteristics of the firing patterns of slowly accommodating neurons were observed, however, with increased concentrations of NT-3. The first alteration of note was a reduction of the interspike intervals of some of the neurons. Heretofore, we have very rarely observed neurons firing $>24$ action potentials in response to a $240 \mathrm{~ms}$ duration stimulus, yet in the case of $10 \mathrm{ng} / \mathrm{ml}$, we observed four neurons that fired over this amount, two with an APmax of 25 and two other neurons with APmax values of 27 and 28. From this set of recordings, therefore, we have observed the fastest interspike intervals to date of $8.9 \mathrm{~ms}$, compared with that noted previously at $10.4 \mathrm{~ms}$.

The intermediate concentrations of NT-3 (7-14 ng/ml) had an additional, unexpected effect on the firing patterns of the basal spiral ganglion neurons. Unlike exposure to $5 \mathrm{ng} / \mathrm{ml}$, after which neurons fire action potentials in a single burst that begins at the onset of current injection (Fig. 2, inset, left series of three traces), application of the higher concentrations caused neurons to fire action potentials in bursts (Fig. 2, inset, right series of three traces). This pattern was rarely observed in apical neurons without neurotrophin supplementation (Mo and Davis, 1997a; Adamson et al., 2002b) and was seen in only 1 of 10 multiple spiking neurons treated with $5 \mathrm{ng} / \mathrm{ml} \mathrm{NT-3}$. In cultures supplemented with 7,10 , and $14 \mathrm{ng} / \mathrm{ml}$ of NT-3, however, there was frequently a gap between the first few action potentials fired at the onset of the stimulus and action potentials observed toward the end of the stimulus pulse (e.g., 10 of 14 in the $10 \mathrm{ng} / \mathrm{ml}$ condition). As the constant-current step injection became more depolarizing, the number of action potentials at the beginning of the stimulus did not increase; instead, additional action potentials accumulated from the end of the stimulus to decrease the length of the gap progressively until it was no longer observed. In addition to
$240 \mathrm{~ms}$ pulses, depolarizing pulses of longer duration were used to test firing patterns. When these neurons were exposed to longer depolarizing step current injections (480-840 ms), many of them showed more complex and irregular bursting patterns.

To determine whether the distinct firing patterns described above were also present in spiral ganglion neurons or unique to high NT-3 concentrations, we performed a separate set of experiments designed to record from spiral ganglion neurons that we have not evaluated previously: those in the midcochlear regions. We chose to compare the slowly accommodating firing patterns of middle spiral ganglion neurons to those displayed by apical neurons. These recordings were taken from neurons isolated separately from either the apex or middle regions and from spiral ganglion cultures in which the location of the neuron was determined with intracellular dyes (see Materials and Methods). Independent of the technique that we used to make recordings, we found that neurons in the middle region did indeed display the unique firing features described above. Slowly accommodating middle spiral ganglion neurons displayed firing patterns either with or without a gap (Fig. 3, $b$ and $a$, respectively), and, furthermore, we found two of these types of neurons with an APmax of 30, thus having the lowest interspike intervals $(8.1 \mathrm{~ms})$ observed to date. When all of the slowly accommodating neurons (firing more than eight action potentials in response to a $240 \mathrm{~ms}$ duration depolarizing stimulus) were evaluated, we observed that the APmax was significantly higher for the middle spiral ganglion neurons $(25 \pm 1.7 ; n=6)$ compared with their apical counterparts $(18.6 \pm 1.1 ; n=8 ; p<0.01)$ (Fig. $3 c$ ). Moreover, the middle neurons had the capability to fire with significantly abbreviated interspike intervals at APmax (9.9 \pm 0.6 $\mathrm{ms})$ compared with the slowly accommodating apical neurons $(13.5 \pm 0.9 \mathrm{~ms} ; p<0.05)$ (Fig. $3 d$ ). Therefore, by recording from neurons located in the middle regions of the ganglion, we were able to determine that the firing patterns observed with various concentration of NT-3 were displayed by spiral ganglion neurons isolated from the ganglion without neurotrophin supplementation.

In addition to the alteration in supra-threshold firing patterns, NT-3 had a clear effect on electrophysiological parameters measured at the threshold voltage for firing an action potential. Threshold level was determined as the first trace triggering an action potential when current injection was increased at steps of 1 pA. Recordings obtained from the vehicle and $10 \mathrm{ng} / \mathrm{ml}$ conditions showed that in the presence of NT-3, it takes longer for the neuron to fire an action potential in response to a threshold stimulus. This feature is quantified as the latency from the onset of the current injection to the peak of the action potential for all of the conditions that were tested (Fig. 4a). As predicted from previous studies, we found that latency measurements were relatively abbreviated in basal neurons not exposed to neurotrophin (control, $8.9 \pm 0.6 \mathrm{~ms}$; vehicle, $9.8 \pm 0.4 \mathrm{~ms}$ ). In contrast, recordings from NT-3-supplemented cultures showed that latencies were significantly increased. Both conditions that used $5 \mathrm{ng} / \mathrm{ml}$, either when 
added at $0 \operatorname{div}(12.4 \pm 1.2 \mathrm{~ms})$ or added at $3 \operatorname{div}(13.6 \pm 1.0 \mathrm{~ms})$, were significantly different from control $(p<0.05)$ and vehicle $(p<0.01)$, respectively. Furthermore, NT-3 concentrations of $7 \mathrm{ng} / \mathrm{ml}$ (14.2 $\pm 1.5 \mathrm{~ms}), 10 \mathrm{ng} / \mathrm{ml}(17.9 \pm 1.0 \mathrm{~ms})$, $14 \mathrm{ng} / \mathrm{ml}(13.4 \pm 1.6 \mathrm{~ms})$, and $20 \mathrm{ng} / \mathrm{ml}$ $(13.2 \pm 0.7 \mathrm{~ms})$ were all significantly different from vehicle $(p<0.01)$. As shown previously for the analysis of APmax, a similar dose-response pattern emerged. The largest change was produced by 10 $\mathrm{ng} / \mathrm{ml} \mathrm{NT}-3$ with lesser effects at the two higher concentrations that were tested. Furthermore, no significant differences were observed between the two $5 \mathrm{ng} / \mathrm{ml}$ conditions in which NT-3 was added to the media at different times $(5 \mathrm{ng} / \mathrm{ml} 0 \mathrm{~d}$ vs $5 \mathrm{ng} / \mathrm{ml} 3 \mathrm{~d}$ ). These findings substantiate the dose-response pattern that we noted for the supra-threshold electrophysiological parameter APmax.

Recordings taken from neurons at the voltage just below threshold for firing revealed a prolonged onset time course that was most obvious in cells treated with $10 \mathrm{ng} / \mathrm{ml} \mathrm{NT-3}$. This electrophysiological parameter was quantified by fitting a single exponential to the onset voltage change in response to step current injections (excluding the initial rapid phase) (Fig. 4b). The quantitative analysis of this parameter for all concentrations showed a dose-response pattern that was consistent with both APmax and latency. Similar to these other parameters, the time course of the onset voltage change showed the greatest difference from vehicle $(4.0 \pm 0.2 \mathrm{~ms})$ at 10 $\mathrm{ng} / \mathrm{ml}(6.68 \pm 0.5 \mathrm{~ms} ; p<0.01)$. Fits of recordings made from 5 $\mathrm{ng} / \mathrm{ml} 3 \mathrm{~d}(5.0 \pm 0.5 \mathrm{~ms}), 7 \mathrm{ng} / \mathrm{ml}(6.4 \pm 0.9 \mathrm{~ms})$, and $20 \mathrm{ng} / \mathrm{ml}$ $(5.4 \pm 0.3 \mathrm{~ms})$ were also significantly different from vehicle $(p<$ $0.05,0.01$, and 0.01 , respectively). The two other comparisons that would be expected to differ, control $(3.8 \pm 0.2 \mathrm{~ms})$ versus 5 $\mathrm{ng} / \mathrm{ml} 0 \mathrm{~d}(4.4 \pm 0.3 \mathrm{~ms})$ and vehicle versus $14 \mathrm{ng} / \mathrm{ml}$ recordings $(4.7 \pm 0.4)$, fell short of achieving statistical significance at $p<$ 0.08 and $p<0.07$, respectively.

Although in previous studies (Adamson et al., 2002a,b; Reid et al., 2004) we had not observed significant differences in threshold between apical and basal neurons or between neurons with and without added neurotrophins (BDNF or NT-3), in the present study there was a tendency for threshold voltage to differ in a manner similar to other electrophysiological parameters (Fig. $4 c$ ). Of the concentrations that were evaluated relative to the vehicle (average threshold, $-46.1 \pm 0.9 \mathrm{mV}$ ), however, only the $10 \mathrm{ng} / \mathrm{ml}$ concentration $(-50.2 \pm 1.1 \mathrm{mV})$ showed a significant difference $(p<0.05)$. Additionally, threshold voltage for cells in the $5 \mathrm{ng} / \mathrm{ml} 0 \mathrm{~d}$ condition $(-46.1 \pm 0.9 \mathrm{mV})$ differed significantly from controls $(-42.2 \pm 0.6 \mathrm{mV} ; p<0.01)$. One complicating factor was the observation that control neurons (untreated; recorded at 3 div) differed significantly from the vehicle neurons (received vehicle solution at 3 div; recorded at 6 div; $p<0.01$ ), indicating that time in culture may affect this parameter. From this comparison, it appears that the longer the cells are maintained in vitro the lower the thresholds. This interpretation was supported somewhat by the lower threshold voltages of the 5 $\mathrm{ng} / \mathrm{ml} 3 \mathrm{~d}$ condition $(-48.1 \pm 1.0)$ relative to the $5 \mathrm{ng} / \mathrm{ml}$ $0 \mathrm{~d}$ category, although the difference was not statistically significant.
An effect of NT-3 on threshold would not be expected to affect the APmax analysis, because these measurements were taken at supra-threshold voltages. However, it could potentially confound our analysis of the electrophysiological parameters that were taken at the threshold level. For example, if the thresholds were generally more hyperpolarized for any particular condition, it would not be unexpected for time-dependent parameters, such as the latency or onset kinetics, to be prolonged. We addressed this issue by evaluating a subset of the data in which only neurons with similar threshold voltages were used; the voltage levels were necessarily different in the two comparisons that we made because threshold levels changed over time in culture. When overlapping threshold levels of -46 to $-36 \mathrm{mV}(p>0.2)$ were used to compare the control and $5 \mathrm{ng} / \mathrm{ml} 0 \mathrm{~d}$ conditions $(n=7$ and 18 , respectively), the latency and onset kinetics remained significantly different $(p<0.01$ and $p<0.05$, respectively). Similarly, a subset of data was considered for the comparison between the vehicle and $10 \mathrm{ng} / \mathrm{ml} \mathrm{NT}-3$ conditions $(-55$ to $-43 \mathrm{mV} ; n=23$ and 13, respectively; $p>0.2$ ); latency differences and onset kinetics remained significantly different ( $p<0.01$ for both comparisons). Therefore, despite the variation in threshold levels, the differences in latency and time course are still evident.

Another parameter that differed between conditions was the decay of the afterhyperpolarization (AHP) (Fig. 4d). $\tau$ Values were obtained from single-exponential fits to the AHP of action potentials fired in response to threshold depolarization. This analysis showed significant differences at the $p<0.01$ level for each of the conditions in which NT-3 was added at 3 div compared with vehicle. At $5,7,10,14$, and $20 \mathrm{ng} / \mathrm{ml}$, the average $\tau$ values were $4.4 \pm 0.5,6.8 \pm 1.8,5.6 \pm 0.6,4.8 \pm 0.9$, and $5.6 \pm 0.7$ ms, respectively. The average $\tau$ for the vehicle condition was $(3.0 \pm 0.2 \mathrm{~ms})$. No significant difference was observed between the control and $5 \mathrm{ng} / \mathrm{ml} \mathrm{NT-3} 0 \mathrm{~d}$ conditions. We also analyzed action potential amplitude, which, in contrast to the time course of the AHP, showed no significant differences with NT-3 application regardless of the concentration used. Therefore, the alterations in the electrophysiological parameters that we noted in Figure 4 were independent of any changes that occurred in the amplitude of the action potential. There was, however, an in- 

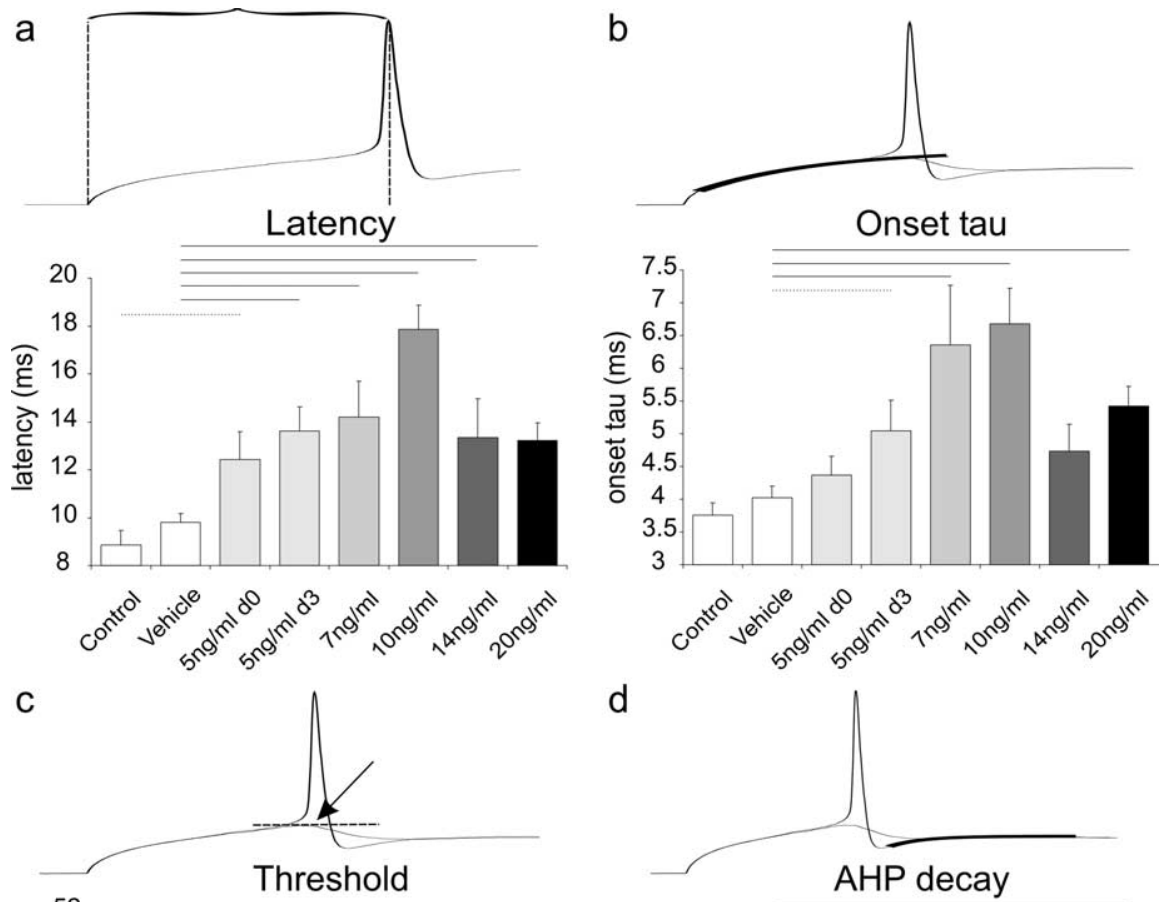

$$
\text { d }
$$

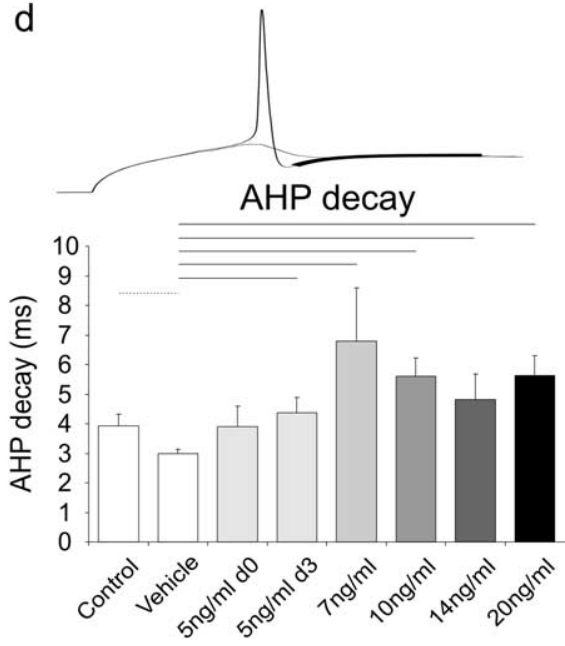

Figure 4. Quantitative comparisons of threshold and subthreshold responses taken from neurons exposed to different concentrations of NT-3. $\boldsymbol{a}$, Latency is measured as the time from the stimulus onset to the peak of the action potential at threshold level. Exposure to NT-3, even at its lowest concentrations, significantly increases the latency of the neuronal response; the greatest

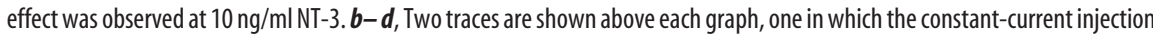
elicited a just subthreshold response and one that elicited a threshold response. $\boldsymbol{b}$, Onset $\tau$ was obtained by fitting a single exponential to the onset depolarization at the subthreshold trace; the initial rapid phase of the waveform was excluded from the fit. The slowest onset kinetics was obtained from neurons exposed to $10 \mathrm{ng} / \mathrm{ml} \mathrm{NT-3.c,} \mathrm{An} \mathrm{approximation} \mathrm{of} \mathrm{the} \mathrm{threshold} \mathrm{voltage}$ level was obtained by measuring the peak voltage of the subthreshold trace. Because of the significantly different threshold levels between the control and vehicle, it appears that the threshold level decreases with time in culture. Nevertheless, the lowest threshold level was obtained at $10 \mathrm{ng} / \mathrm{ml}$, which was significantly different from the vehicle. $\boldsymbol{d}$, The time course of the AHP was measured by fitting a single exponential to its decay phase. AHP decay was most altered in neurons exposed to $7 \mathrm{ng} / \mathrm{ml}$ NT-3, although all concentrations had significant effects. The significant difference between vehicle and control may indicate that the

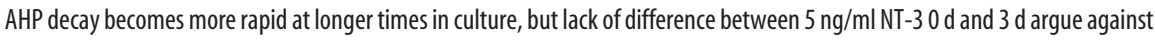
this conclusion. Error bars represent SEM.

crease in the action potential amplitude over time in culture. Comparison of action potential amplitude between control $(91.3 \pm 2.0 \mathrm{mV})$ and vehicle $(100.9 \pm 1.4 \mathrm{mV})$ recordings, as well as between $5 \mathrm{ng} / \mathrm{ml} \mathrm{NT}-3$ added at $0 \mathrm{div}(94.7 \pm 1.4 \mathrm{mV})$ and $3 \mathrm{div}$ $(102.4 \pm 1.2 \mathrm{mV})$ revealed significant differences, both at $p<$ 0.01 .

Another parameter that appears to have little apparent sensitivity to NT-3 is the magnitude of the voltage sag in response to hyperpolarizing constant-current step injections. This classic voltage pattern (Fig. 5) is indicative of the presence of the hyperpolarization-activated currents $\left(I_{\mathrm{h}}\right)$. Previous studies have shown that spiral ganglion neurons possess $I_{\mathrm{h}}$ currents with a wide range of steady state voltages of activation in spiral ganglion neurons isolated from restricted regions of the cochlea (Mo and Davis, 1997b). We wished to determine, therefore, whether NT-3 would affect the magnitude or time course of voltage changes in response to step hyperpolarizing constant-current injections that reflect the activity of the $I_{\mathrm{h}}$ currents. To avoid the contribution of other low-voltage-activated currents found in spiral ganglion neurons, such as Kv1.1 (Mo et al., 2002), measurements were made from relatively hyperpolarized levels $(-185 \pm 3 \mathrm{mV})$ to the plateau level at the end of a $240 \mathrm{~ms}$ duration current injection. Our analysis showed no significant differences between any of the conditions (Fig. 5a). Furthermore, the time course of the hyperpolarizing sag, fitted with a single exponential (Fig. 5b), was relatively unaffected by application of NT-3 . We noted a decreasing time course of the response with NT-3 exposure; this, however, was only significant at the $20 \mathrm{ng} / \mathrm{ml}$ concentration $(30.2 \pm 2.1 \mathrm{~ms})$ when compared with the vehicle $(24.2 \pm 2.1 \mathrm{~ms} ; p<$ 0.05).

The transformation of the basal spiral ganglion neurons into slowly accommodating, "apical-like" neurons could be accounted for in two different ways. Because NT-3 has been shown to promote survival of spiral ganglion neurons in vivo and in vitro (Avila et al., 1993; Mou et al., 1997; Hansen et al., 2001; Fritzsch et al., 2004), one mechanism could be that NT-3 selectively promotes the survival of a subpopulation of spiral ganglion neurons. Our laboratory has shown previously that putative type II spiral ganglion neurons differ in the base from their type I counterparts by demonstrating slow accommodation, longer latencies, and prolonged membrane time constants (Reid et al., 2004), similar to neurons exposed to the appropriate concentrations of NT-3 in the present study. Therefore, it is possible that NT-3 may simply enhance the survival of type II neurons in our cultures, thus increasing the preponderance of this electrophysiological phenotype. An alternative scenario is that NT-3 alters gene expression or posttranscriptional events such that the same neurons that formerly possessed the numbers and types of channels and their regulatory elements to shape fast responses elaborate a different complement of voltage-gated ion channels that produce a slower electrophysiological phenotype.

Because we did not observe any substantial differences in the electrophysiological phenotype between neurons exposed to NT-3 immediately after being placed in culture $(5 \mathrm{ng} / \mathrm{ml} 0 \mathrm{~d})$ and those exposed to NT-3 after a delay of $3 \mathrm{~d}(5 \mathrm{ng} / \mathrm{ml} 3 \mathrm{~d})$, we hypothesized that our results are consistent with the second scenario proposed above. We reasoned that NT-3 would promote 
neuronal survival predominantly in cultures that were exposed to NT-3 at the time that they were isolated for tissue culture in which the greatest cell death would be predicted to occur and that NT-3 would have minimal effects on neuronal survival when added to the media after 3 div. To test this, we counted the number of neurons in culture dishes that were prepared according to the protocol used to generate the data for Figure 1. Matched cultures from a single litter of mice were divided into four conditions: control (untreated), $5 \mathrm{ng} / \mathrm{ml} 0 \mathrm{~d}$ (NT-3 added at plating, survival assessed at 3 div), vehicle (vehicle solution added at 3 div, survival assessed at 6 $\mathrm{div}$ ), and $5 \mathrm{ng} / \mathrm{ml} 3 \mathrm{~d}$ (NT-3 added at $3 \mathrm{div}$, survival assessed at 6 div). The total numbers of neurons were counted from four separate experiments after cells had been labeled with anti- $\beta$-tubulin antibody to distinguish the neurons from the background layer of satellite cells (Fig. 6). Aside from the expected significant increase in survival observed when NT-3 was added immediately after tissue isolation $(p<$ 0.01 ), the control, vehicle, and NT-3 $3 \mathrm{~d}$ conditions showed similar numbers of surviving neurons. Therefore, the change in electrophysiological phenotype induced by NT-3 added at 3 div cannot be accounted for by differential survival when the cells were recorded from at 6 div. Had this been the case, the number of surviving cells in the vehicle condition should have been significantly less than in the $5 \mathrm{ng} / \mathrm{ml}$ $3 \mathrm{~d}$ condition. Instead, the numbers of cells in the two conditions were virtually identical $(99.6 \pm 20.6$ and $96.0 \pm 22.0$ neurons, respectively), indicating that NT-3 is responsible for altering the numbers and/or types of voltage-gated ion channels in the basal spiral ganglion neurons, thus changing a fast firing neuron into one with slowed kinetics and accommodation.

\section{Discussion}

NT-3 has a profound effect on the electrophysiological signature of postnatal spiral ganglion neurons in vitro. This is especially evident in the present study in which NT-3 was applied to the primary auditory neurons isolated from the base of the cochlea. In addition to transforming rapidly accommodating neurons into slowly accommodating ones, NT-3 also has an impact on latency, onset time course, threshold, and decay of the afterhyperpolarization. Most of these parameters, however, change nonmonotonically with increases in NT-3 concentration, with the peak effect occurring at $10 \mathrm{ng} / \mathrm{ml}$ and declining sharply at higher concentrations. These results point out two important observations: first, the striking responsiveness of the spiral ganglion neurons to small alterations in NT-3 concentration and second, the complex relationship between neurotrophin concentration and firing patterns.

The exquisite sensitivity of spiral ganglion neurons to NT-3 concentration has marked functional significance in a highly organized peripheral auditory system in which the majority of neurons have precise synaptic contacts with the sensory receptors (Ryugo, 1992; Raphael and Altschuler, 2003) and in which NT-3 expression is systematically regulated, with the highest levels in the apical cochlea and the lowest levels in the basal cochlea (Fritzsch et al., 1997). From this relationship, one might predict that the electrophysiological profile of the spiral ganglion is organized in a manner similar to the distribution of NT-3 such that a smooth and regular gradient in firing patterns is displayed from apex to base. Although the broad outline of this type of pattern has been observed by evaluating restricted regions of the ganglion taken from the apex and base, there is also an overlying heterogeneity in some of the electrophysiological features that belies this simplified view (Adamson et al., 2002b). Additionally, the 
nonmonotonic dose-response patterns observed in the present study adds a new wrinkle to the analysis, thus indicating that the precise NT-3 concentration, in addition to how it is localized, is important for regulating the endogenous membrane properties of spiral ganglion neurons. If the NT-3 concentration exceeds 10 $\mathrm{ng} / \mathrm{ml}$ anywhere along the apical-to-basal gradient, then one might expect that the simple NT-3 gradient would be transformed into a more complex electrophysiological map. For example, the predicted effects on neuronal firing patterns would be greatly altered if the effective NT-3 concentration reached 10 $\mathrm{ng} / \mathrm{ml}$ at the middle, instead of at the apex of the cochlea. In this scenario, rather than observing the highest APmax in the apical tip region, this firing feature would be found toward the middle of the cochlea with intermediate APmax values localized toward the apex. Experiments presented herein, showing that neurons located in the middle regions of the spiral ganglion fire the greatest number of action potentials during a $240 \mathrm{~ms}$ step depolarizing constant-current injection (up to 30 action potentials), indicate that a complex pattern similar to that outlined above most likely exists in the spiral ganglion.

As has been shown in many developmental processes, simple one-dimensional gradients can generate complex patterns (Wolpert, 1996). This could be especially relevant for NT-3, because it binds promiscuously to a number of high-affinity trk receptors as well as the low-affinity receptor p75NTR (Segal, 2003), thus potentially initiating complex cellular effects depending on the receptor combinations activated. However, for this feature to be used effectively, spiral ganglion neurons must possess more than one receptor type. A number of studies have shown that during development, this is, in fact, the case. In addition to p75NTR, spiral ganglion neurons possess both trkB and trkC high-affinity tyrosine kinase receptors (Ylikoski et al., 1993; Mou et al., 1997; Cochran et al., 1999; Gestwa et al., 1999). It is possible, therefore, that at higher concentrations $(>10 \mathrm{ng} / \mathrm{ml})$, NT-3 could bind to the trkB receptor in addition to the trkC receptor (Kuruvilla et al., 2004), thus evoking unique electrophysiological characteristics. This would be consistent with previous studies from our laboratory that have shown that activating the trkB receptor with BDNF alters the endogenous membrane properties and channel types in such a way as to generate faster accommodation and kinetics (Adamson et al., 2002a). Furthermore, preliminary experiments using a combination of NT-3 and BDNF show firing patterns that are closer to the BDNF alone conditions (M. A. Reid and R. L. Davis, unpublished observations), whereas similar concentrations of NGF, which should bind exclusively to p75NTR in these neurons having no trkA receptors, is without effect (Adamson et al., 2002a). These types of considerations, therefore, might lead one to the straightforward prediction that by activating both receptor types with high NT-3 concentrations, the slower features observed at lower NT-3 concentrations would be overridden by the faster features that we had observed by activating the trkB receptor with BDNF, which is generally what we observed in the present study.

In addition to the scenario that neuronal responses are solely controlled by NT-3 concentration, one might expect that other mechanisms would also be in place. It has been shown that neurotrophin receptor binding can also be controlled by the number and isoforms of neurotrophin receptors present (Barbacid, 1994). For example, in avian dorsal root ganglion neurons, alternative splicing yields a trkB isoform missing 11 amino acids in the extracellular domain that not only restricts BDNF binding efficiency but also has a profound reduction on NT-4 and NT-3 activation of the receptor (Hapner et al., 1998). Furthermore,
NT-3 binding to TrkA receptors in sympathetic ganglia is downregulated by enhanced p75NTR, whereas NGF binding to the same high-affinity receptor is unaffected by the presence of p75NTR (Kuruvilla et al., 2004). These types of complex interactions are also likely in the spiral ganglion where multiple forms of the trkB and trkC receptors have been identified (Gestwa et al., 1999), autocrine mechanisms are present (Hansen et al., 2001), and BDNF, NT-3, and trkB receptor gene expression is tonotopically distributed (Fritzsch et al., 1997; Schimmang et al., 2003).

Another important aspect of NT-3 effects on postnatal spiral ganglion neurons is that it appears to alter the phenotype of individual neurons rather than altering the neuronal population by favoring the survival of neurons with slow firing features. This conclusion is consistent with the results that we observed from culture protocols and cell counts evaluated in the present study. Furthermore, because we were able to obtain recordings from control cultures just before the application of NT-3 (3 div), which had predominantly rapid accommodation and fast kinetics, we were able to conclude that the endogenous membrane properties of neurons exposed to NT-3 at 3 div were transformed into slowly accommodating ones with prolonged kinetics. This would suggest that mechanisms other than selective survival account for the robust alterations that were observed in the present study. Because we had noted previously changes in voltage-gated ion channel density with immunocytochemical studies (Adamson et al., 2002a), we assume that part of the mechanism involves altered gene expression that underlies changes in current density (Levine et al., 1995; Jimenez et al., 1997; Baldelli et al., 2000). However, from the time courses that we chose to evaluate in the present study, we cannot rule out that more immediate modifications may also be involved, such as those revealed for glutamate receptors (Levine et al., 1998; Arvanov et al., 2000; Balkowiec et al., 2000) as well as in some types of voltage-gated ion channels (Kafitz et al., 1999; Tucker and Fadool, 2002). Moreover, recent studies have shown that growth factors can alter the surface expression of both voltage- and ligand-gated ion channels via extranuclear, Akt-dependent signaling pathways (Blair et al., 1999; Brami-Cherrier et al., 2002; Wang et al., 2003; Ning et al., 2004; Chae et al., 2005). Cytoplasmic activation of signaling cascades has explicitly been demonstrated in spiral ganglion neurons to enhance their survival to depolarizing stimuli via cAMP activation of protein kinase A, possibly via the Akt effector (Bok et al., 2003); therefore, we may expect that similar mechanisms may also be in place to regulate channel surface expression in these cells. Because our protocol is able to separate the survival actions of NT-3 from its role in specification of electrophysiological phenotype, we expect that the spiral ganglion neurons may be an excellent model system to study the molecular mechanisms that contribute to these distinct processes.

The seemingly simple peripheral ganglion in the auditory system that transmits the initial encoded electrical signals from the sensory receptors in the cochlea into the CNS is a unique model system in which to study the complex interactions between neurotrophins and their receptors. Not only do the differential effects of neurotrophins on spiral ganglion neurons indicate that signaling cascades of their activated trk receptors are most likely different (Huang and Reichardt, 2003), they also suggest a strong functional role for the promiscuous binding of NT-3 to other trk receptors. This unique feature of NT-3 binding could be used to produce a complex neural electrophysiological pattern from the relatively simple gradient displayed by NT-3 along the tonotopic axis of the cochlea. The challenge in future experiments will be to discover the limits and distribution of the heterogeneity observed 
in the spiral ganglion and illuminate the functional significance of this complexity.

\section{References}

Adamson CL, Reid MA, Davis RL (2002a) Opposite actions of brainderived neurotrophic factor and neurotrophin-3 on firing features and ion channel composition of murine spiral ganglion neurons. J Neurosci 22:1385-1396.

Adamson CL, Reid MA, Mo ZL, Bowne-English J, Davis RL (2002b) Firing features and potassium channel content of murine spiral ganglion neurons vary with cochlear location. J Comp Neurol 447:331-350.

Arvanov VL, Seebach BS, Mendell LM (2000) NT-3 evokes an LTP-like facilitation of AMPA/kainate receptor-mediated synaptic transmission in the neonatal rat spinal cord. J Neurophysiol 84:752-758.

Avila MA, Varela-Nieto I, Romero G, Mato JM, Giraldez F, Van De Water TR, Represa J (1993) Brain-derived neurotrophic factor and neurotrophin-3 support the survival and neuritogenesis response of developing cochleovestibular ganglion neurons. Dev Biol 159:266-275.

Baldelli P, Forni PE, Carbone E (2000) BDNF, NT-3 and NGF induce distinct new $\mathrm{Ca} 2+$ channel synthesis in developing hippocampal neurons. Eur J Neurosci 12:4017-4032.

Balkowiec A, Kunze DL, Katz DM (2000) Brain-derived neurotrophic factor acutely inhibits AMPA-mediated currents in developing sensory relay neurons. J Neurosci 20:1904-1911.

Barbacid M (1994) The Trk family of neurotrophin receptors. J Neurobiol 25:1386-1403.

Blair LA, Bence-Hanulec KK, Mehta S, Franke T, Kaplan D, Marshall J (1999) Akt-dependent potentiation of $\mathrm{L}$ channels by insulin-like growth factor-1 is required for neuronal survival. J Neurosci 19:1940-1951.

Bok J, Zha XM, Cho YS, Green SH (2003) An extranuclear locus of cAMPdependent protein kinase action is necessary and sufficient for promotion of spiral ganglion neuronal survival by cAMP. J Neurosci 23:777-787.

Brami-Cherrier K, Valjent E, Garcia M, Pages C, Hipskind RA, Caboche J (2002) Dopamine induces a PI3-kinase-independent activation of Akt in striatal neurons: a new route to cAMP response element-binding protein phosphorylation. J Neurosci 22:8911-8921.

Chae KS, Martin-Caraballo M, Anderson M, Dryer SE (2005) Akt activation is necessary for growth factor-induced trafficking of functional $\mathrm{K}(\mathrm{Ca})$ channels in developing parasympathetic neurons. J Neurophysiol 93:1174-1182.

Cochran SL, Stone JS, Bermingham-McDonogh O, Akers SR, Lefcort F, Rubel EW (1999) Ontogenetic expression of trk neurotrophin receptors in the chick auditory system. J Comp Neurol 413:271-288.

Davis RL (2003) Gradients of neurotrophins, ion channels, and tuning in the cochlea. Neuroscientist 9:311-316.

Felix H, Johnsson LG, Gleeson M, Pollak A (1990) Quantitative analysis of cochlear sensory cells and neuronal elements in man. Acta Otolaryngol Suppl 470:71-79.

Fritzsch B, Farinas I, Reichardt LF (1997) Lack of neurotrophin 3 causes losses of both classes of spiral ganglion neurons in the cochlea in a regionspecific fashion. J Neurosci 17:6213-6225.

Fritzsch B, Tessarollo L, Coppola E, Reichardt LF (2004) Neurotrophins in the ear: their roles in sensory neuron survival and fiber guidance. Prog Brain Res 146:265-278.

Gestwa G, Wiechers B, Zimmermann U, Praetorius M, Rohbock K, Kopschall I, Zenner HP, Knipper M (1999) Differential expression of trkB.T1 and trkB.T2, truncated trkC, and p75(NGFR) in the cochlea prior to hearing function. J Comp Neurol 414:33-49.

Hansen MR, Zha XM, Bok J, Green SH (2001) Multiple distinct signal pathways, including an autocrine neurotrophic mechanism, contribute to the survival-promoting effect of depolarization on spiral ganglion neurons in vitro. J Neurosci 21:2256-2267.

Hapner SJ, Boeshore KL, Large TH, Lefcort F (1998) Neural differentiation promoted by truncated trkC receptors in collaboration with p75(NTR). Dev Biol 201:90-100.
Huang EJ, Reichardt LF (2003) Trk receptors: roles in neuronal signal transduction. Annu Rev Biochem 72:609-642.

Jimenez C, Gireldez F, Represa J, Garcia-Diaz JF (1997) Calcium currents in dissociated cochlear neurons from the chick embryo and their modification by neurotrophin-3. Neuroscience 77:673-682.

Kafitz KW, Rose CR, Thoenen H, Konnerth A (1999) Neurotrophin-evoked rapid excitation through TrkB receptors. Nature 401:918-921.

Kuruvilla R, Zweifel LS, Glebova NO, Lonze BE, Valdez G, Ye H, Ginty DD (2004) A neurotrophin signaling cascade coordinates sympathetic neuron development through differential control of TrkA trafficking and retrograde signaling. Cell 118:243-255.

Levine ES, Dreyfus CF, Black IB, Plummer MR (1995) Differential effects of NGF and BDNF on voltage-gated calcium currents in embryonic basal forebrain neurons. J Neurosci 15:3084-3091.

Levine ES, Crozier RA, Black IB, Plummer MR (1998) Brain-derived neurotrophic factor modulates hippocampal synaptic transmission by increasing $N$-methyl-D-aspartic acid receptor activity. Proc Natl Acad Sci USA 95:10235-10239.

Liberman MC, Oliver ME (1984) Morphometry of intracellularly labeled neurons of the auditory nerve: correlations with functional properties. J Comp Neurol 223:163-176.

Miller JM, Chi DH, O’Keeffe LJ, Kruszka P, Raphael Y, Altschuler RA (1997) Neurotrophins can enhance spiral ganglion cell survival after inner hair cell loss. Int J Dev Neurosci 15:631-643.

Mo Z-L, Davis RL (1997a) Endogenous firing patterns of murine spiral ganglion neurons. J Neurophysiol 77:1294-1305.

Mo Z-L, Davis RL (1997b) Heterogeneous voltage dependence of inward rectifier currents in spiral ganglion neurons. J Neurophysiol 78:3019-3027.

Mo ZL, Adamson CL, Davis RL (2002) Dendrotoxin-sensitive K(+) currents contribute to accommodation in murine spiral ganglion neurons. J Physiol (Lond) 542:763-778.

Mou K, Hunsberger CL, Cleary JM, Davis RL (1997) Synergistic effects of BDNF and NT-3 on postnatal spiral ganglion neurons. J Comp Neurol 386:529-539.

Nadol Jr JB, Burgess BJ, Reisser C (1990) Morphometric analysis of normal human spiral ganglion cells. Ann Otol Rhinol Laryngol 99:340-348.

Ning K, Pei L, Liao M, Liu B, Zhang Y, Jiang W, Mielke JG, Li L, Chen Y, El-Hayek YH, Fehlings MG, Zhang X, Liu F, Eubanks J, Wan Q (2004) Dual neuroprotective signaling mediated by downregulating two distinct phosphatase activities of PTEN. J Neurosci 24:4052-4060.

Raphael Y, Altschuler RA (2003) Structure and innervation of the cochlea. Brain Res Bull 60:397-422.

Reid MA, Flores-Otero J, Davis RL (2004) Firing patterns of type II spiral ganglion neurons in vitro. J Neurosci 24:733-742.

Rubel EW, Fritzsch B (2002) Auditory system development: primary auditory neurons and their targets. Annu Rev Neurosci 25:51-101.

Ryugo DK (1992) The auditory nerve: peripheral innervation cell body morphology, and central projections. In: The mammalian auditory pathway: neuroanatomy (Popper AN, Fay RR, eds), pp 34-93. New York: Springer.

Schimmang T, Tan J, Muller M, Zimmermann U, Rohbock K, Kopschall I, Limberger A, Minichiello L, Knipper M (2003) Lack of Bdnf and TrkB signalling in the postnatal cochlea leads to a spatial reshaping of innervation along the tonotopic axis and hearing loss. Development 130:4741-4750.

Segal RA (2003) Selectivity in neurotrophin signaling: theme and variations. Annu Rev Neurosci 26:299-330.

Tucker K, Fadool DA (2002) Neurotrophin modulation of voltage-gated potassium channels in rat through $\operatorname{TrkB}$ receptors is time and sensory experience dependent. J Physiol (Lond) 542:413-429.

Wang Q, Liu L, Pei L, Ju W, Ahmadian G, Lu J, Wang Y, Liu F, Wang YT (2003) Control of synaptic strength, a novel function of Akt. Neuron 38:915-928.

Wolpert L (1996) One hundred years of positional information. Trends Genet 12:359-364.

Ylikoski J, Pirvola U, Moshnyakov M, Palgi J, Arumae U, Saarma M (1993) Expression patterns of neurotrophin and their receptor mRNAs in the rat inner ear. Hear Res 65:69-78. 